\title{
The Impact of Reference Group on Purchase Intention: A Case Study in Distinct Types of Shoppers
}

\section{Danupol Hoonsopon and Wilert Puriwat}

\begin{abstract}
Past studies explore the effect of purchase intention by reference group in various situations. However, the roles of a reference group (private and public group) on the purchase intention of the distinctive types of shoppers have been overlooked. Drawing from the social influence theory, using experimental research, and analyzing data with $t$-Test and ANOVA, the findings show that utilitarian shoppers tend to have higher purchase intention when a private group is used for information cues. But, a reference group does not have an impact on the purchase intention of hedonic and social shoppers. This research theoretically contributes to social influence theory by revealing that a reference group has a diverse effect on purchase intention in different stimuli.
\end{abstract}

D. Hoonsopon $(\varangle) \bullet$ W. Puriwat

e-mail: danupol@cbs.chula.ac.th; wilert@cbs.chula.ac.th 